\title{
Computational fluid dynamics analysis in the ductless whole- house air conditioning system
}

\author{
Rie Tasaka ${ }^{1}$, Sayaka Kindaichi ${ }^{1,{ }^{*}}$, and Daisaku Nishina $^{1}$, Mitsuhiko Maeoki ${ }^{1}$ \\ ${ }^{1}$ Hiroshima University, Department of architecture, Hiroshima Prefecture, Japan
}

\begin{abstract}
Recently, the heat load for space heating in residential houses has been reduced as airtightness, and thermal insulation performance has been improving even in moderate climate regions of Japan. In such situations, the heat load can be handled by one room air-conditioner with high energy efficiency. We report the results of computational fluid dynamics (CFD) analysis of an indoor thermal environment and the airflow distribution during the space heating operation in a ductless house air conditioning system, in which heated air from a room air conditioner installed in a thermal-insulated basement space is distributed throughout the building using air inlets on the floor in each story and open-door rooms without ductworks. To determine the adequate size and position of the air inlets on the floor in this heating system, we evaluated the air circulation performance for changes in the conditions of the air inlets by CFD analysis for a standard two-storey house model in Japan. The results suggest that the air temperature distribution is markedly different in the size and position of the air inlets on the floor. Large volumes of airflow through the openings in the building resulted in maintaining the rooms at a temperature range of 17 to 24 degrees uniformly. These results also provide information for system and building designs for effective space heating and for proper usage when choosing to open or close air inlets in the operational phase.
\end{abstract}

\section{Introduction}

Japanese space heating systems are different from European systems. In North and Eastern Europe, district heating systems, which currently have a $10 \%$ share in the EU, have significant market penetration. In contrast, Central and Southern European countries have an almost non-existent market [1] [2]. Moreover, ground source heat is often used for heating [3] [4]. Air-to-air heat pump systems are among the most widespread in buildings in most south European countries, particularly in those without any other heating system, since they are used for both heating and cooling. They are much more energy-efficient than other types of electric heaters, especially in regions with mild winters [5].

In the moderate climate region of Japan, it is typical to provide heating by having a heat-pump room air-conditioner in each room. Recently, the heat load for space heating in residential houses has reduced as the airtightness, and thermal insulation performance has been improving even in the moderate climate regions of Japan. In such situations, the heat load can be handled by only one room air-conditioner with high energy efficiency. However, the vertical temperature difference increases in the convection air conditioning system [6].

We expect to promote the ductless house airconditioning system, in which warm air from a room air conditioner installed in a thermal-insulated basement space is distributed throughout the building using air inlets on the floor on each story and open-door rooms without ductworks in Japan, where a central air conditioning system in residential houses is not common. Convection heating by warm air from air inlets and radiation heating by under-floor heating can be effected simultaneously in this heating system. Because the floor panel is heated to a higher temperature than indoor air, the vertical temperature difference reduces, and the radiation environment becomes much better.

We report the results of computational fluid dynamics (CFD) analysis of an indoor thermal environment and airflow distribution during the space heating operation in this heating system.

We evaluated the air circulation performance for changes in the air inlet conditions by CFD analysis for a standard two-storey house model in Japan to determine the adequate size and position of the air inlets on the floor in the heating system.

\section{Methods}

\subsection{House model}

The house model is a standard two-storey house in Japan, which has a basement space depth of $910 \mathrm{~mm}$ (Fig. 1). This house has a Japanese-style room, a kitchen, one living-dining room and three bedrooms, and its total area is $120.08 \mathrm{~m}^{2}$. The $\mathrm{U}$ value was set to $0.32 \mathrm{~W} /\left(\mathrm{m}^{2} \mathrm{~K}\right)$ for the outer skin. The size of the air inlets on the first floor is $1200 \mathrm{~mm} \times 100 \mathrm{~mm}$ and that on the second floor

\footnotetext{
* Corresponding author: kindaichi@hiroshima-u.ac.jp
} 
is $2000 \mathrm{~mm} \times 100 \mathrm{~mm}$; however, that in the toilet on each floor and powder room is $600 \mathrm{~mm} \times 100 \mathrm{~mm}$ because of limited space. For ventilation, eight air supply ports and five air exhausting ports of the same size $(100 \mathrm{~mm} \times 100 \mathrm{~mm})$ are installed on the walls at 2 $\mathrm{m}$ above the floor. Fresh air flows into the room through the air supply ports without heat recovery and flows out through the air exhausting ports. The room air conditioner installed under the floor just below the living-dining room supplies warm air to the whole basement space and collects return air from the room space at the air inlet on the top. The heating power of the room air conditioner is controlled by a temperature sensor in the return air inlet in the actual use. The doors in the rooms are opened to distribute warm air to the whole house.

\subsection{CFD analysis}

Numerical modelling of the airflow and temperature distribution was carried out using Autodesk CFD 2019 software, adopting a finite element approach with the k- $\varepsilon$ turbulence model equations (Table 1). The airflow equations are solved for the three-dimensional Cartesian system using the SIMPLE-R algorithm. The convection and diffusion terms are integrated using the streamline upwind discretization scheme. Convergence was considered to have been reached when the sum of the normalised residuals for each of the airflow equations was less than $10^{-4}$. View factors are calculated by the Monte Carlo method, and the heat transfer by radiation is calculated with an emissivity of glass of 0.8 , and 0.92 for other solid materials. The airflow model equations are solved with the conditions for the supply diffuser, extract, and solid boundaries. The house model has totally 808,942 meshes by automatic mesh generation and partially manual division at the ait inlets with $30 \mathrm{~mm}$ width. Heat load calculation software calculates the maximum heat load of the model house in the ductless house air conditioning system in winter at Hiroshima city, called the BEST program, and consequently, it is about $4.45 \mathrm{~kW}$ in 2006 at $-0.8^{\circ} \mathrm{C}$. The room air conditioner blows warm air at $887 \mathrm{~m}^{3} / \mathrm{h}$ and 35 ${ }^{\circ} \mathrm{C}$ to cover the heat load.

\subsection{Simulation cases}

Simulation cases are as follows: In case A, all air inlets on the floor are open, but all doors between the rooms are closed; In case B, all air inlets and doors are open; In case $\mathrm{C}$, air inlets in the Japanese room are closed compared to case B.

\section{Results and discussion}

The simulation results are shown in Fig. 3 for the spatial distribution of temperature and airflow. Fig. 4 shows the results for the average room temperature and Fig. 5 shows the total amount of airflow in the horizontal direction between the rooms and the vertical direction through the air inlets and the stairs. First, the effect of

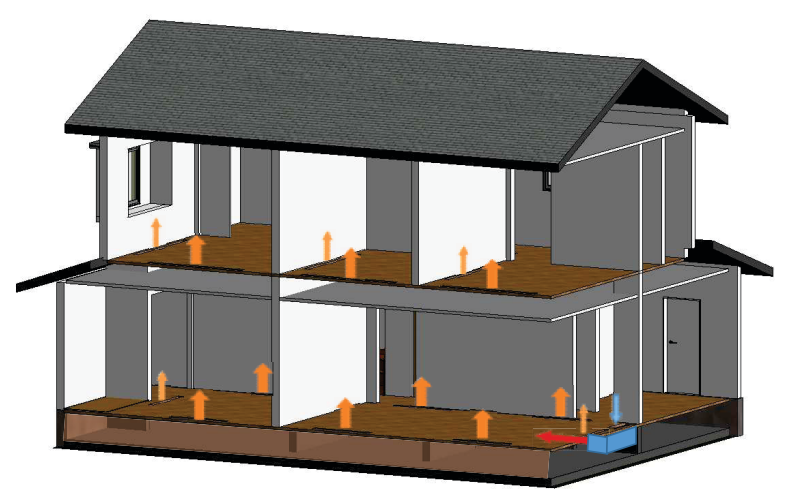

Fig. 1. Modelling house

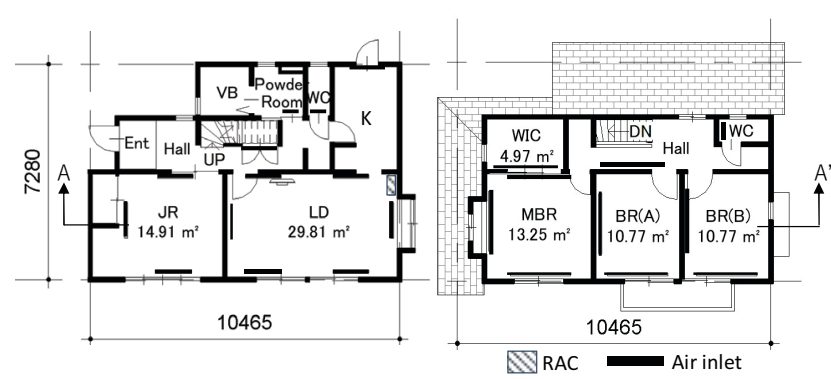

Fig. 2. Position of air inlets on the floor and room air conditioner under the floor; LD : Living and dining room, K : KitchenJR : Japanese-style room, MBR : Master bed room, BR : Bed room

Table 1. Analysis conditions

\begin{tabular}{ll}
\hline Analysis software & Autodesk CFD 2019 \\
Analysis mode & Steady state analysis \\
Turbulent model & Standard k- $\varepsilon$ model \\
Discretization method & Finite element method \\
Advection scheme & Monotone streamline upwind scheme \\
Algorithm & SIMPLE-R method \\
$\begin{array}{l}\text { Maximum number of } \\
\text { calculation }\end{array}$ & 1000 times \\
Convergence assessment & 10 \\
\hline
\end{tabular}

Table 2. Boundary conditions

\begin{tabular}{lll}
\hline & $\begin{array}{l}\text { Exterior walls } \\
\text { Roof }\end{array}$ & $-0.8^{\circ} \mathrm{C}$ \\
$\begin{array}{l}\text { Temperature of } \\
\text { the outer skin }\end{array}$ & $\begin{array}{l}\text { Windows } \\
\text { Outer foundation } \\
\text { Bottom foundation }\end{array}$ & $2.2{ }^{\circ} \mathrm{C}$ \\
\hline Ventilation & $\begin{array}{l}\text { Exhaust air volume } \\
\text { Supply air volume }\end{array}$ & $120 \mathrm{~m}^{3} / \mathrm{h}$ \\
\hline
\end{tabular}

Table 3. Room air conditioner

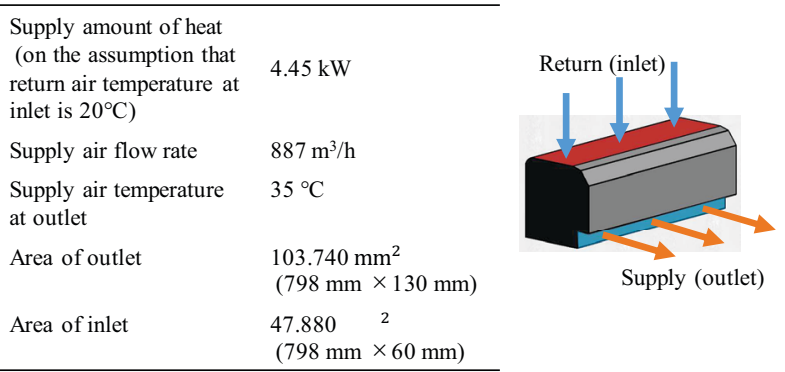



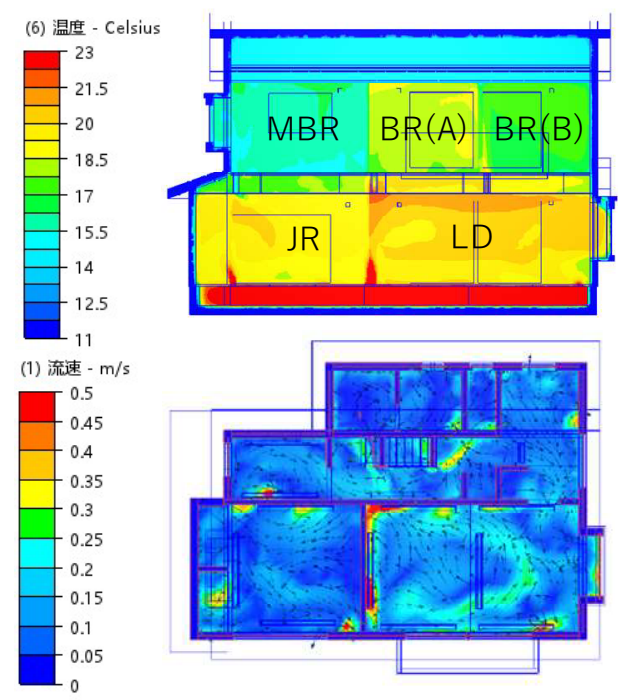

Case A
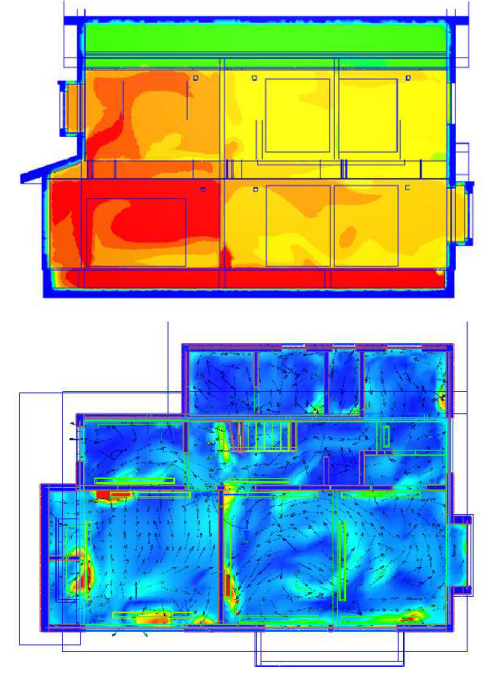

Case B
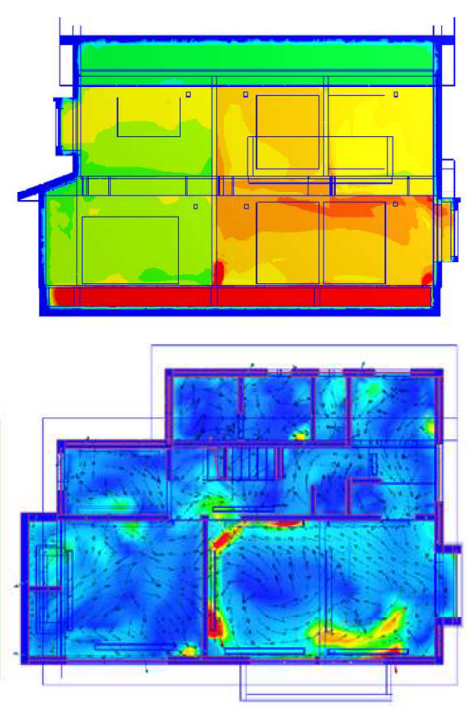

Case C

Fig. 3. Simulated temperatures at section A-A' and verosity at $110 \mathrm{~cm}$ high above the $1^{\text {st }}$ floor

closing the doors on the thermal environment is described using case A and case B. Although the temperature in the LD is the same, at approximately 20 ${ }^{\circ} \mathrm{C}$ in both the cases, the temperature in the other rooms is different. Case A shows lower temperatures than case B. Especially low temperatures below $18^{\circ} \mathrm{C}$ are recorded on the $2^{\text {nd }}$ floor in case A. This may be due to the shortage of the upward flow from the $1^{\text {st }}$ floor to the $2^{\text {nd }}$ floor. Case A shows less velocity around the stairs in Fig. 3, which results in about half the amount of vertical upward flow on the $2^{\text {nd }}$ floor in Fig. 5 compared to case B. These results indicate that the openness between rooms is an important point to facilitate air circulation in the whole building and increase the heating efficiency in the heating system.

The amount of vertical upward flow on the $1^{\text {st }}$ floor is similar to the input condition $\left(887 \mathrm{~m}^{3} / \mathrm{h}\right)$ in the three cases (Fig. 5). However, the cases show different velocities in each air inlet on the $1^{\text {st }}$ floor, which results in different temperature distributions (Fig. 3). For instance, case A shows a relatively small velocity in JR than in LD, whereas opening of the doors allows us to equalize the velocity in case $\mathrm{B}$.

In this simulation, case B shows a good thermal environment. However, the average temperature in JR is above $22{ }^{\circ} \mathrm{C}$, which may be inefficient because the frequency of use of Japanese rooms is usually less than that of LD in typical Japanese houses. Accordingly, we carried out Case C, where all the air inlets are closed in JR. Although there are no air inlets in JR in case $\mathrm{C}$, the average temperature is kept at about $18{ }^{\circ} \mathrm{C}$ in JR because warm air, from the air inlets in $\mathrm{LD}$, is relayed to JR through the door instead of the air inlets on the floor. Therefore, a large amount of horizontal airflow is observed in case $\mathrm{C}$ compared to other cases (Fig. 5). As a result, case $\mathrm{C}$ shows higher temperatures on the east side, including LD and lower temperatures on the west side, including JR, whereas case B shows the opposite distribution (Fig. 3). Except for JR, case C does not have significant differences in the average temperature compared to case B. Given the actual usage of the rooms, and case $\mathrm{C}$ can be one of the alternatives to provide a good thermal environment.

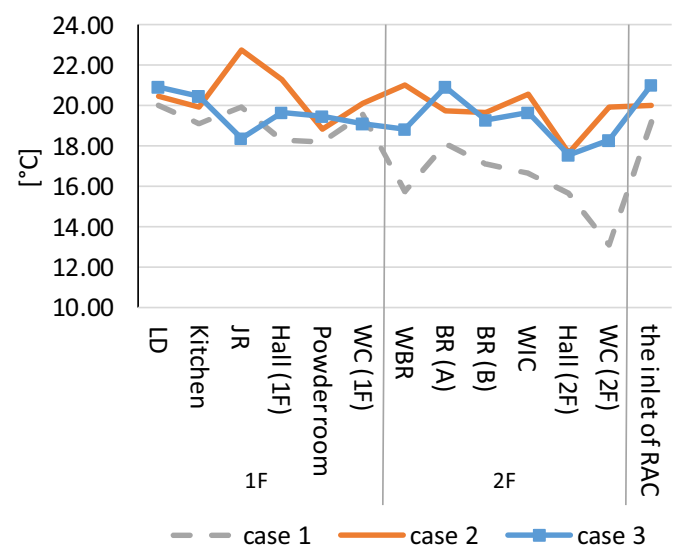

Fig. 4. Average temperatures at $110 \mathrm{~cm}$ high above the floor

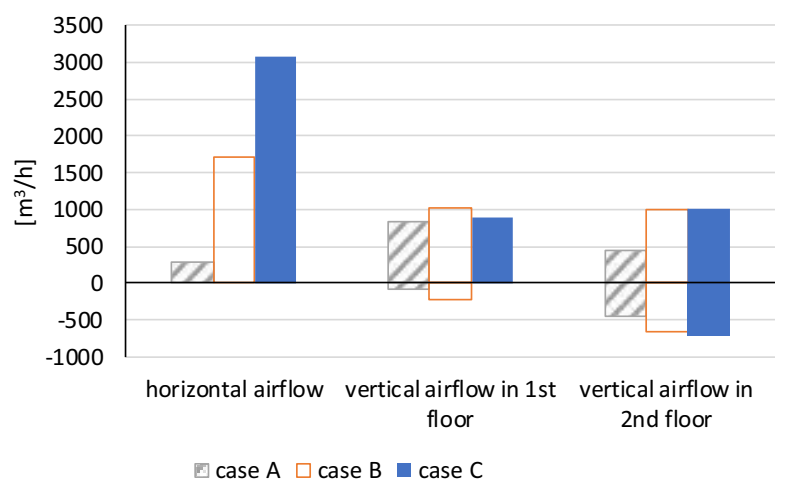

Fig. 5. The total amounts of horizontal airflow through the doors (scalar) and vertical airflow in $1^{\text {st }}$ and $2^{\text {nd }}$ floors through the slits and stair (positive: upward, negative : downward) 


\section{Conclusion}

We reported a thermal environment formed in a ductless house air conditioning system using a room air conditioner by CFD analysis. The results suggest that an open-door spatial design is essential in delivering warm air from the basement to the $2^{\text {nd }}$ floor without air ducts, and to achieve a pleasant thermal environment. The position of the air inlets on the floor also affects the thermal environment. However, the effect of the air inlets is relatively less than that of doors in the scope of this analysis. In one case, all the air inlets in all the rooms were opened, and there was a good thermal environment, whereas in another case, the air inlets were partially closed, also showing a permissible thermal environment. Closing of the air inlets in the rooms that are not used may lead to temperature increase in other rooms, implying an increase in the heating efficiency.

In further studies, we will continue CFD analysis with other air-supply conditions for various heating loads and provide information about the adequate design and operation of the heating system.

We would like to thank Editage (www.editage.com) for English language editing.

\section{References}

1. Dodoo, L. Gustavsson, R. Sathre, Building energyefficiency standards in a life cycle primary energy perspective, Energy and Buildings, 43, 1589-1597 (2011)

2. P. Ovchinnikov, A. Borodinecs, K. Strelets, Utilization potential of low temperature hydronic space heating systems: A comparative review, Building and Environment, 112, 88-98 (2017)

3. A. M. Omer, Ground-source heat pumps systems and applications, Renewable and Sustainable Energy Reviews, 12, 344-371 (2008)

4. E. Akpinar, A. Hepbasli, A comparative study on exergetic assessment of two ground-source (geothermal) heat pump systems for residential applications, Building and environment, 42, 20042013 (2007)

5. G. Martinopoulos, K. T. Papakostas, A. M. Papadopoulos, A comparative review of heating systems in EU countries, based on efficiency and fuel cost, Renewable and Sustainable Energy Reviews, 90, 687-699 (2018)

6. C. Karmann, S. Schiavon, F. Bauman, Thermal comfort in buildings using radiant vs. all-air systems: A critical literature review, Building and Environment, 111, 123-131 (2017) 